\title{
Numerical investigation on the performance of ducted propeller
}

\author{
Aldias Bahatmaka ${ }^{1,3 *}$, Dong-Joon $\mathrm{Kim}^{2}$, Deddy Chrismianto $^{3}$, Joga Dharma Setiawan ${ }^{4}$, and \\ Aditya Rio Prabowo ${ }^{1}$ \\ ${ }^{1}$ Pukyong National University, Interdisciplinary Program of Marine Design Convergence, 48513 \\ Busan, South Korea \\ ${ }^{2}$ Pukyong National University, Department of Naval Architecture and Marine Systems Engineering, \\ 48513 Busan, South Korea \\ ${ }^{3}$ Diponegoro University, Department of Naval Architecture, 50269 Semarang, Indonesia \\ ${ }^{4}$ Diponegoro University, Department of Mechanical Engineering, 50269 Semarang, Indonesia
}

\begin{abstract}
As a part of the important thing in ship design is propeller design. Propeller its self has many kinds of the design. This study investigates the effect on the performance of ducted propeller. The investigation was carried out by solving the Navier-Stokes equations with the Computational Fluid Dynamics (CFD) method. These simulations were compared in accordance SHUSKIN nozzle that has 3 types of design. Each type of thruster model indicates different force and torque. Thus, for the analysis will be generated by each model and it can be discovered that which model has the most optimal for the thrust. The analysis by using CFD indicates the change of fluid flow around the ducted propeller. The results showed that the nozzle on the propeller will give the extra of thrust for the performance of propeller.
\end{abstract}

\section{Introduction}

Many remote operated vehicle (ROV) have been developed for the maintenance and inspection of ocean structures. Most of them in practical use are self-propulsive with umbilical cable. To avoid the effects of noise force from the cable a free swim power would be ideal, but most are tethered, then the electrical power can be supplied and control signals and data obtained can be transmitted. A self-propulsive ROV can be guided to target more accurately than towed one. Consequently, a tethered self-propulsive which is usually used to inspect and maintain ocean structures [1]. In ship hydrodynamics, fixed propellers, also named screw propellers, have an important place among the propulsion systems to propel a ship. Propeller design is to obtain the optimum propeller which applies to minimum power requirements and against maximum efficiency conditions at an adequate revolution number. Usually two methods are used in the propeller design. The first is use diagrams obtained from the open water propeller experiments for systematic propeller series. The second is to use mathematical method (lifting line, lifting surface, vortex-lattice, boundary element method)

*Corresponding author: aldias@pukyong.ac.kr 
based on circulation theory [2]. The characteristics of flow around propeller ducted with decelerating nozzle have been analysed [3]. Form from the previous research, the nozzle produces a decrease in the propulsive efficiency. Thus, the nozzle is important to use in propeller as ROV thruster.

\section{Design model}

\subsection{ROV design}

In this research, ROV project in Fig.1 has been designed [4] and the dimension is presented in Table 1.

Table 1. Principle dimensions of ROV

\begin{tabular}{|c|c|}
\hline Item & mm \\
\hline Length & 602 \\
\hline Beam & 409 \\
\hline Height & 290 \\
\hline
\end{tabular}

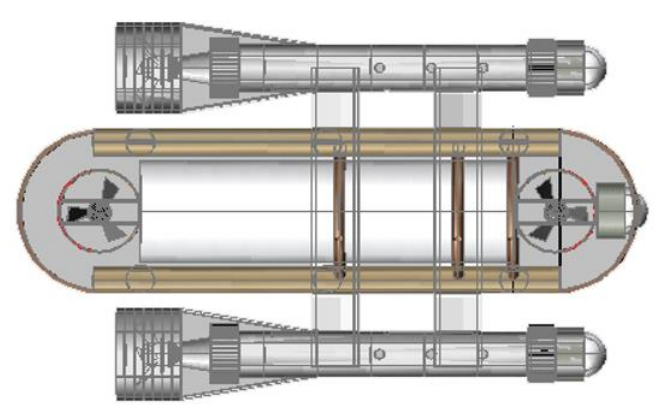

Fig. 1. ROV project design.

\subsection{Propeller design}

The propeller dimension and geometry design are listed in Table 2.

Table 2. Principle dimensions of propeller

\begin{tabular}{|c|c|}
\hline Item & Unit \\
\hline Diameter & $130 \mathrm{~mm}$ \\
\hline Pitch & $78 \mathrm{~mm}$ \\
\hline $\begin{array}{c}\text { Amount of } \\
\text { blade }\end{array}$ & 5 blades \\
\hline $\begin{array}{c}\text { Expanded } \\
\text { BAR }\end{array}$ & 0.75 \\
\hline $\begin{array}{c}\text { Rake of angle } \\
\text { (B5-75) }\end{array}$ & 10.00 degree \\
\hline $\begin{array}{c}\text { Rake of angle } \\
\text { (Ka5-75) }\end{array}$ & 15.00 degree \\
\hline
\end{tabular}


In this case, the propeller dimension was chosen by the product sold in the market. And by this dimension, propeller was designing in 3D model. For the design used 2 types of design, B-series (B5-75) and Kaplan-series (Ka5-75) as shown in Fig.2.

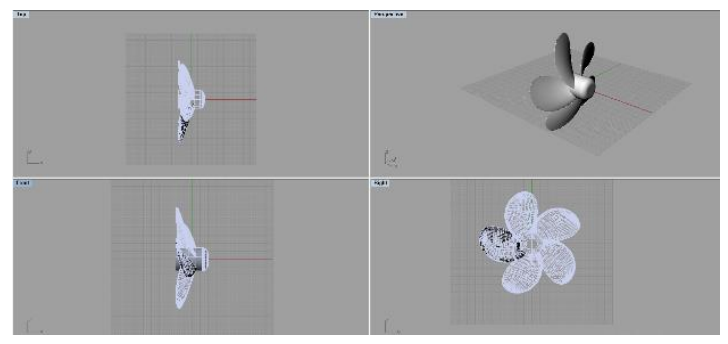

(a)

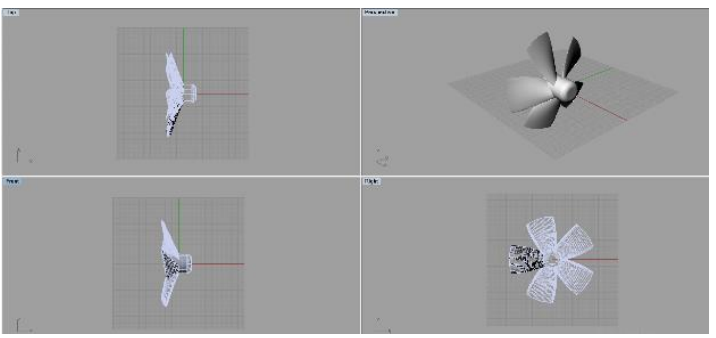

(b)

Fig. 2. Geometry models for propeller: (a) B-series (B5-75), (b) Kaplan-series (Ka5-75).

\subsection{Nozzle design}

For the calculation of nozzle, there are three types of nozzle as shown in the Fig. 3 and the dimension is listed in the Table 3.

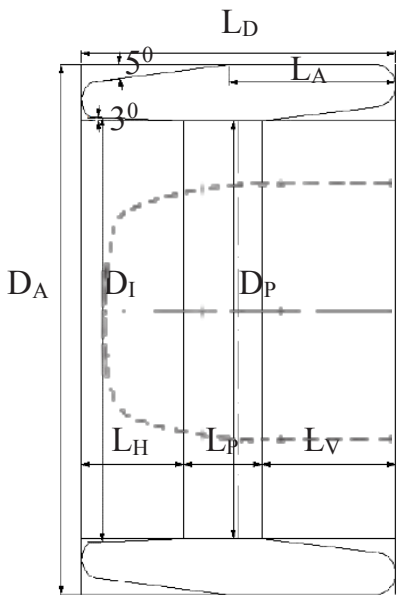

(a)

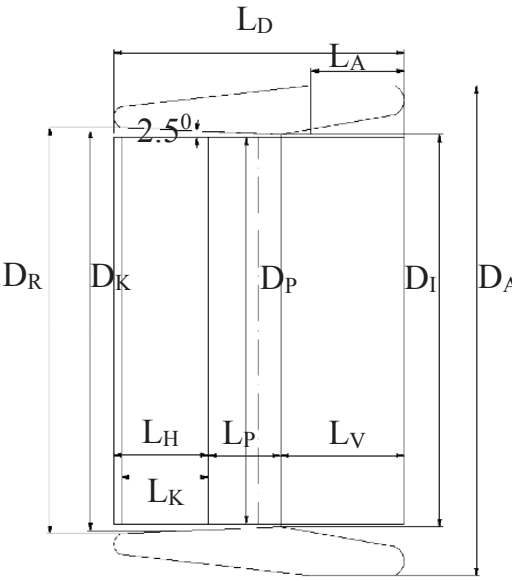

(b)

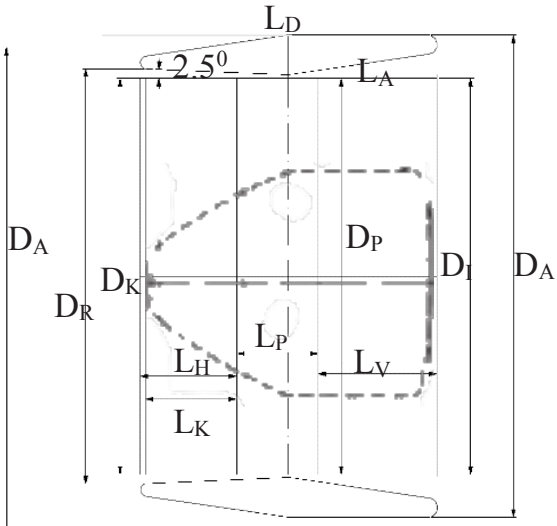

(c)

Fig. 3. Geometry models for nozzle: (a) type A, (b) type B, (c) type C. 
Table 3. Principle dimensions of nozzle

\begin{tabular}{|c|c|c|c|}
\hline Item & Type A & Type B & Type C \\
\hline LD/DP & 0.75 & 0.75 & 0.75 \\
\hline DI /DP & 1.015 & 1.015 & 1.015 \\
\hline Limits & $20 \mathrm{~mm}$ & $20 \mathrm{~mm}$ & $20 \mathrm{~mm}$ \\
& $<$ & $<$ & $<$ \\
& $(\mathrm{DI}-\mathrm{DP})$ & $(\mathrm{DI}-\mathrm{D})$ & $(\mathrm{DI}-\mathrm{DP})$ \\
& $<$ & $<$ & $<$ \\
& $60 \mathrm{~mm}$ & $60 \mathrm{~mm}$ & $60 \mathrm{~mm}$ \\
\hline LA/LD & 1.25 & 0.32 & 0.50 \\
\hline LP/LD & 0.53 & 0.25 & 0.50 \\
\hline LV/LD & 0.27 & 0.425 & 0.40 \\
\hline LH/LD & 0.40 & 0.325 & 0.35 \\
\hline
\end{tabular}

\section{Methodology}

For the numerical on analysis was using computational fluid dynamics method (CFD). The CFD is one of method which is using numerical and algorithm for predicting and solving the engineering problems related fluid flow. Application of CFD to the completion of the flow problem. Reynold Averaged Navier-Stokes equations (RANS) have been developed based in the concept that a velocity and length scale are sufficient to described the effect of turbulence in flow. In a statically steady flow, every variable can be written as Eq.1 the sum of a time averaged value ( $\bar{U}$ ) and fluctuation (u').

$$
U=\bar{U}+u^{\prime}
$$

Where the time -averaging velocity component is defined as Eq.2

$$
\bar{U}=\frac{1}{T} \int_{0}^{T} U d t
$$

Where $\mathrm{T}$ is the averaging interval. This interval must be large compared to the typical time scale of the fluctuations. Thus, if $\mathrm{T}$ is large enough, $(\bar{U})$ does not depend on the time at which the averaging is started. Several steps for calculation such as geometry, mesh, setup, solution and result. Boundary condition was calculating for the open water propeller was presented [5]. The boundary condition can be shown in Fig.4.

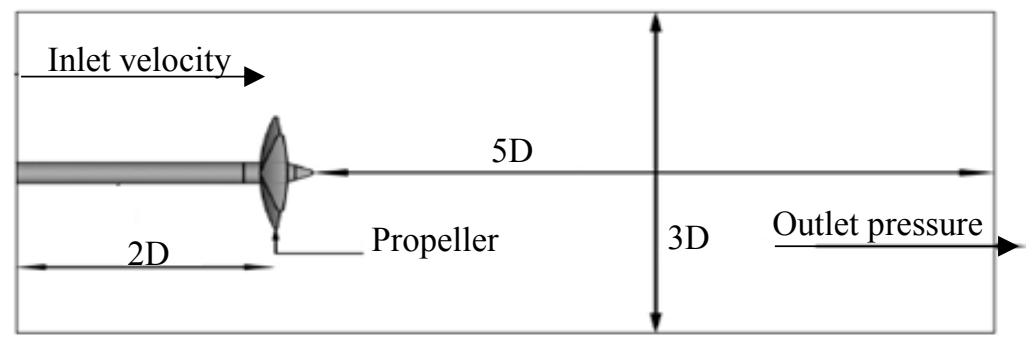

Fig. 4. Boundary condition for open water propeller. 


\section{Validation of thruster}

In this research to validate the result of the test model, used the software test result that already existed and was conducted [6]. Validation of underwater thruster is used to determine the exact boundary condition. ROV thruster using CFD-based software. Reference is taken from the validated model for the testing thruster. Used propeller type of Ka5-75 series and based on the theory of Wageningen [7]. The open water propeller characteristics conventionally were presented in form of the thrust and torque coefficient $\mathrm{K}_{\mathrm{T}}$ and $\mathrm{K}_{\mathrm{Q}}$ in term of the advanced coefficient $\mathrm{J}$ which is given as Eq.3, 4 and 5 .

$$
\begin{array}{r}
K_{T}=\frac{T}{\rho n^{2} D^{4}} \\
K_{Q}=\frac{T}{\rho n^{2} D^{5}} \\
J=\frac{V_{A}}{n D}
\end{array}
$$

\section{Meshing process}

For this process, there were the same input of parameters and produced different results for the mesh size. Fig.5 is represented as sample of meshing of the models. All of the nozzle's meshing size as shown in the Table 4.

Table 4. Formatting sections, subsections and subsubsections.

\begin{tabular}{|l|c|r|r|}
\hline \multicolumn{2}{|c|}{} & Nodes & Elements \\
\hline \multirow{2}{*}{ Type A } & B-Series & 151053 & 845769 \\
\cline { 2 - 4 } & Kaplan & 125480 & 702840 \\
\hline \multirow{2}{*}{ Type B } & B-Series & 204080 & 1146817 \\
\cline { 2 - 4 } & Kaplan & 179164 & 1007934 \\
\hline \multirow{2}{*}{ Type C } & B-Series & 239314 & 1343789 \\
\cline { 2 - 4 } & Kaplan & 214573 & 1206703 \\
\hline
\end{tabular}

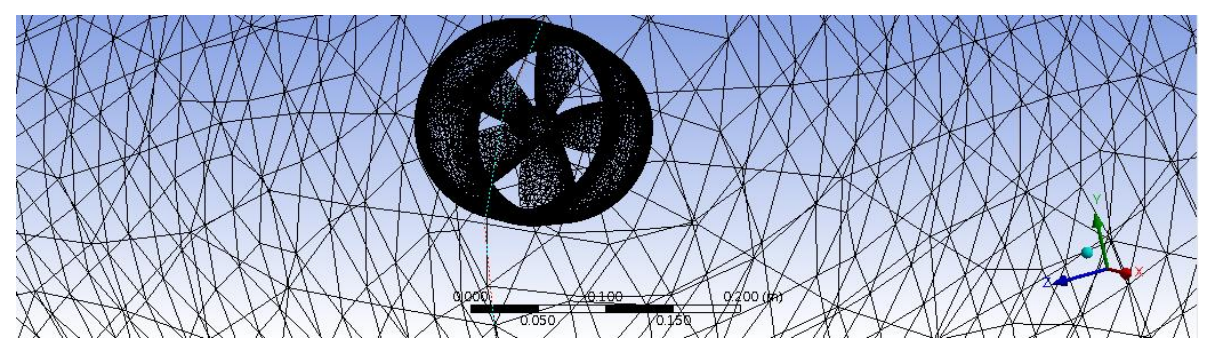

Fig. 5. Meshing of model. 


\section{Result and discussion}

\subsection{Streamline simulation}

For the simulation of streamline, the input for all types were same. The rotational speed is $300 \mathrm{rpm}$. The results of streamline is presented in Fig.6.
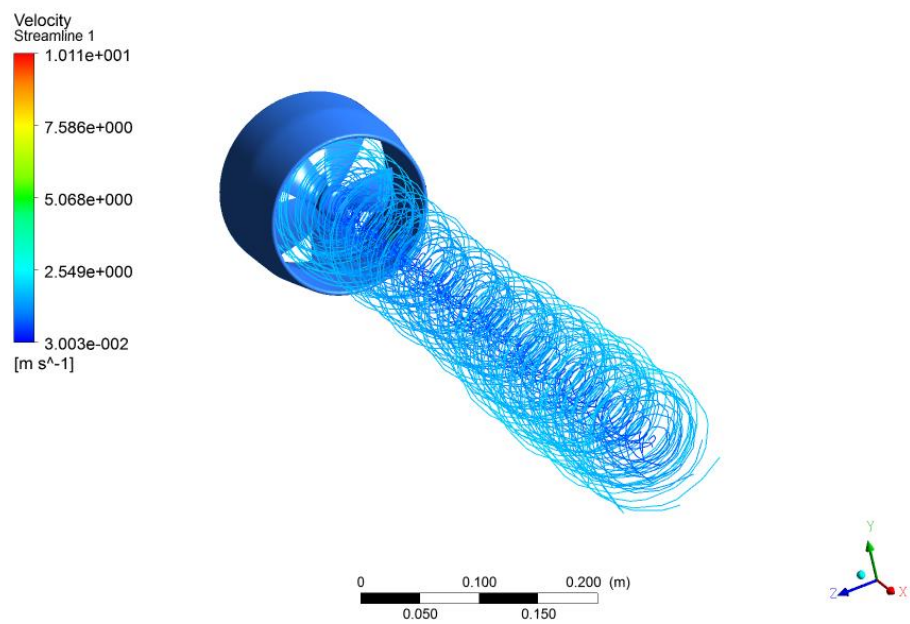

Fig. 6. Streamline of model.

\subsection{Pressure Contour simulation}

This process was indicating the pressure distribution on the blade area. The results of pressure contour as shown in Fig.7.
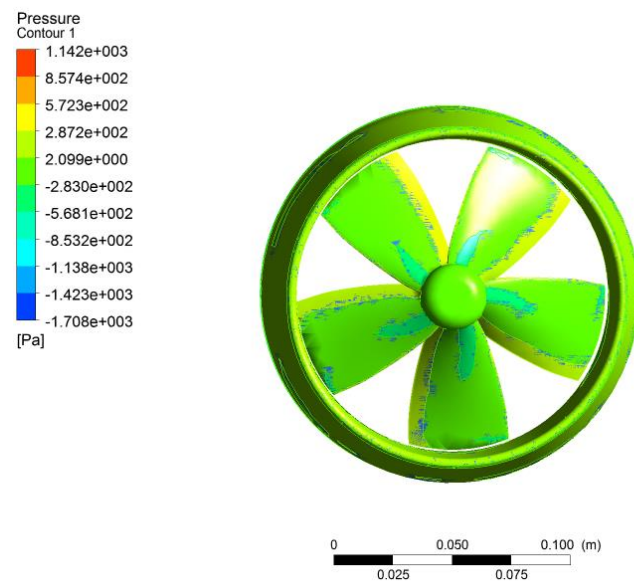

Fig. 7. Pressure contour of model. 


\subsection{Discussion}

From the analysis of CFD method, it can be seen on the Table 5. For the B-series and Table 6. For Kaplan series. The changes of the force as clearly shown in Fig. 8 and the change of the torque shown in Fig.9.

Table 5. Results of force and torque for B-series.

\begin{tabular}{|c|c|c|c|c|}
\hline Output & $\begin{array}{c}\text { Propeller } \\
\text { Only } \\
\text { (P) }\end{array}$ & P+NA & P+NB & P+NC \\
\hline Force (N) & 1.67 & 2.06 & 2.12 & 2.26 \\
\hline Torque (Nm) & 0.016 & 0.020 & 0.021 & 0.023 \\
\hline
\end{tabular}

Table 6. Results of force and torque for Kaplan-series.

\begin{tabular}{|c|c|c|c|c|}
\hline Output & $\begin{array}{c}\text { Propeller } \\
\text { Only } \\
\text { (P) }\end{array}$ & P+NA & P+NB & P+NC \\
\hline Force (N) & 2.02 & 2.34 & 2.50 & 2.53 \\
\hline Torque (Nm) & 0.020 & 0.022 & 0.023 & 0.024 \\
\hline
\end{tabular}

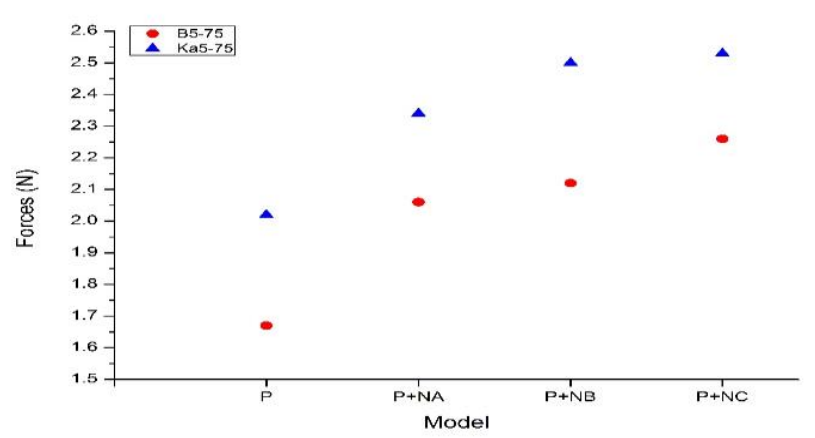

Fig. 8. Chart of force (T) on $300 \mathrm{rpm}$.

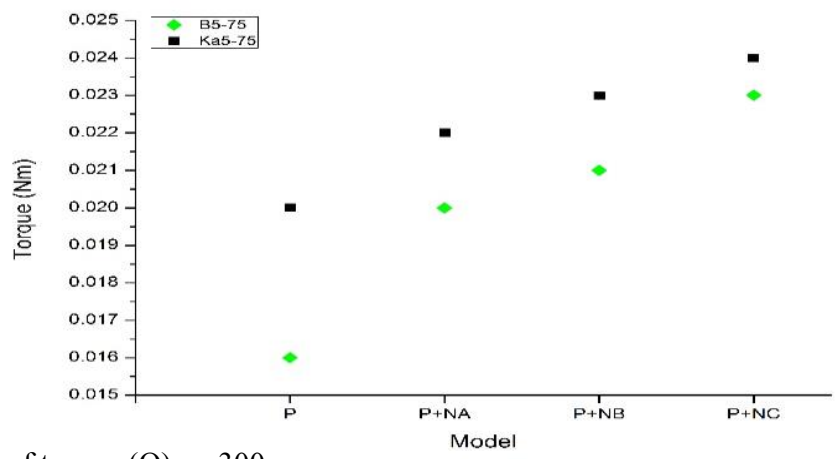

Fig. 9. Chart of torque (Q) on $300 \mathrm{rpm}$. 
In this paper, we have described the specification and the design concepts of ducted propeller as the thruster of ROV. From 6 models, B-series (B5-75) and Kaplan-series (Ka575) with nozzle type A, B, and C. Based on the simulations which were conducted, can be concluded that the highest of force (T) was model Kaplan-series (Ka5-75) with type $\mathrm{C}$ of nozzle. The model could produce $2.53 \mathrm{~N}$ or $25.24 \%$ of extra thrust. The lowest of torque (Q) was model of B-series (B5-75) with type A of nozzle. Thus, the best model will be used for ROV thruster is model of Kaplan-series (Ka5-75) with type $\mathrm{C}$ of nozzle.

\section{Conclusions}

The present work described that the numerical investigation by CFD method has been demonstrated to be more effective as the problem solver for determining the ducted propeller performances. Nozzle can produce the extra thrust for the propeller and Kaplan series with type $\mathrm{C}$ nozzle is the best model for ROV thruster.

\section{Acknowledgement}

The authors would like to thank for the support of the BK21 plus MADEC human resource development group in 2016, Pukyong National University for providing the facilities in this research.

\section{References}

1. N. Masahiko, H. Kajiwara, W. Koterayama, Ocean Eng. 28, 1-43 (2000)

2. S.Ekinci, Brodogradnja 62.2, 123:129 (2011)

3. R. Bontempo, M. Cardone, M. Manna, Applied Ocean Research 58, 322-330 (2016)

4. Adriono et al, DIPO ROV design for exploration robot in Indonesia (Diponegoro University, Semarang, 2013)

5. C. Parra, Numerical investigation hydrodynamic performances of marine propeller (University of Galati, Galati, 2013)

6. Muljowidodo, Indian Journal of Marine Science 38, 338-345 (2009)

7. M. M. Barnitsas, D. Ray, P. Kinley, Kt, Kq, and efficiency curves for the Wageningen B-series propellers (1981) 